\title{
A Proposal for an Advanced Smart System of Vehicle Accidents Detection
}

\author{
Muna Khamis Juma $A L$ \\ Mukhaini \\ Khoula Al Harthy
}

\author{
Middle East College \\ Middle East College
}

In Oman, statistics show that vehicle accidents cause negative effects at the social and economic level resulting in high mortality and injuries. Heavy losses indirectly affect both people and the property of the country. Last year, the percentage of road accidents across Oman was about $33.3 \%$ compared to 2017 , road accidents accounted for $28.8 \%$ less than in 2018. Furthermore, there were many minor accidents in difficult geographic areas in Oman that resulted in deaths because of delay and difficulty the rescues teams had to discover the accidents locations. In order to reduce road traffic fatalities, the rescue teams? took an effective way. They reduced the time between accidents and the emergency team sending to the scene by using detection system via sensors connected in cars. The aim of this project is to propose an advanced system for accident tracking and monitoring. This research targets the result to reduces the number of serious injuries and death tolls and enable the competent authorities to monitor any accident in all vehicles registered at the system. The modified waterfall methodology has been used. This methodology? contains five different stages that contribute to the successful implementation of this system by tracking the project step by step for these stages you can refer to any previous stage in order to amend documents and jobs therein.

\section{Introduction}

This research describes the suffering of Oman about a lot of vehicle accidents which cause negative effects at the social and economic level and high mortality and injuries and heavy losses indirectly affect people and the property of the country and society. Last year, the percentage of road accidents across Oman was about 33.3\% compared to 2017, road accidents accounted for $28.8 \%$ less than in 2018. Accordingly, the competent authorities in the Sultanate of Oman have made considerable efforts in reducing vehicle accidents in 2018, thereby reducing the material and human losses, where statistics showed National Center for Statistics and Information (NCSI) to low accident rate to $29 \%$. (Bhattacharjee, 2018)

Economic construction is developing rapidly. People's living standards are improving. Traffic accidents occurs frequently, causing the loss of life and public property of the country. Traffic accidents have become a grave concern in the national interest. A bad emergency causes many deaths. The mortality rate may increase. Last year, the rate of belt users was estimated at $1 \%$ and that was possible through assisted technological improvements. In addition, in order to reduce road traffic fatalities, the authorities took an effective way; they reduced the time between the accidents and the emergency team is sent to the scene. To determine accidents, detection system about Accidents was used via sensors connected in cars. These regulations were sent forthwith to the competent authorities in emergency cases, analysis shows that time reduction between the accident and sending a medical team causing a 6\% reduction in mortality. (Butt, 2016)

Furthermore, there are many car accidents in our lives that make us think of how to solve them. The biggest problem we face is that many accidents occur, no one knows about them. The reason is that the roads are very long in Oman, where the length of the streets is huge to the large area of the Sultanate, it has a total area of about $309,500 \mathrm{~km}$. 


\section{Journal of Student Research}

Fourth Middle East College Student Research Conference, Muscat, Sultanate of Oman

In addition, there are many minor incidents which result in deaths due to delays in ambulance and assistance. The main reason for this is the lack of knowledge of the location of the accident or the difficulty of describing the location of the accident. And here, we chose this project to build a system which could help locate the incident and vehicle details and its owner and the level of the incident whether it is (simple, medium, and strong). On the other hand, the accident category is to assist the competent authorities to know the details of the accident and needs, for example (police, ambulance, and civil defense). Furthermore, the project is a developed system the competent authorities can identify any incident for all vehicles that are connected to the system. Where there are sensors in vehicles which detects any collision of the vehicle and determines the degree of the collision to send information to the system making it easier for them to know the details of the incident and its location leading to the timely arrival of the competent authorities without delay. Also, sensors sense other whether there is any fire in the car, the system calculates the information received from the sensors. Where the system will request a vehicle location via GPS using a link to location information, then analyze the data received by the system, the system sends notifications to the competent authorities.

\section{Section 1}

An accidents detection technology and prevention are one of the most important techniques in saving people's lives. Therefore, we proposed an effective technique to overcome the flaws of the current system, because most accidents occur today because of alcohol, excess speed, sleep and recklessness in driving. Accordingly, we proposed a new system for accident prevention, and we used different sensors to monitor the speed and a GPS device to send the location of the accident to the rescue team in case of failure of the sensor. Accidents cause significant losses in people's lives, which increased the number of deaths by $17.4 \%$ during the period 2011-2011.

Furthermore, the prevention system has been designed to reduce the number of accidents. Unfortunately, the accident rate remains a serious problem that has not yet been resolved. In this case, we suggest a new technique for speed reduction system. The use of sound waves is placed in the car to discover the distance between them and the other car so we can reduce the speed of the car and not to collide with some. (Priyanga, Rajesh Kumar and J.Yamini, 2014)

We are looking for something that saves people's lives from accidents, if we can provide emergency services at the time of the accident, we will be able to save many lives and solve the problem of death. The accident detection system has been implemented using GPS, GSM, GPRS, which has the advantage of detecting accidents through speed control because it is difficult to control the speed of the car daily

Global Positioning System (GPS): Is a technology developed by the US Department of Defense (DOD) for military use. It was previously available for civil use and used for a wide range of applications locations, direction, speed, timing, survey, logistics services, traffic management, etc.

GPS reception: GPS technology has become more accurate and cconomically reliable. So it is necessary to have a sensitive and accurate GPS device in the cars to get a signal for the system. Accordingly, we must obtain a site identification system to submit additional information about the location where the accident occurred, and thus the team will be sent to rescue without delay, the location is also determined by satellite. Therefore, we provide accurate data up it makes it easier for the emergency team to save people's lives. At present, Google Maps provides good services to reach a specific location using coordinates.

GSM modem: Uses GSM / GPRS modem to send accident sites, so we can control the modem by the control unit.

Microcontroller Unit (MCU): It is the heart of the system and receives data from GPS the accident 


\section{Journal of Student Research}

Fourth Middle East College Student Research Conference, Muscat, Sultanate of Oman

is detected by the treated data and the incident location is sent by the controller unit.

Detection system: The system has been designed to reduce the mortality rate caused by delay in rescuing seriously injured people and to overcome defects in the system, modern systems should be used as sensors and sound waves sensor.We can also easily detect the vibration sensor placed near the airbag, which opens at the time of the accident where the bags open and some vibrations occur, the controller automatically starts the GSM module by sending an emergency message to the rescue team in order to inform the accident rescue team via the GPS location.

Nowadays, the Sultanate of Oman suffers from a lot of problems related to traffic accidents that always occur and may increase significantly year after year. Traffic accidents are one of the most important problems in societies which entail a loss of development negatively on the state. Consequently, traffic accidents result in many problems, including the number of road traffic deaths and injuries increased by 33.3\% in 2018 compared to 2017.

Loss of a family member or an entire family in road accidents due to the speed, overtaking, and talk by phone and others cause increased mortality rate and thus may affect the economic development of the country. On the other hand, after studies conducted on this subject, it was found that accidents occurred in 2018 more than 2017 by 3.3\%.

The delay of rescue in most cases, and that through the inability of the injured access to the competent authorities or there are no people to report the incident to give him timely treatment, also thus may lead to deterioration of health status and arrive into the stage of danger.

Delay or difficulty in locating the incident by the competent authorities, because sometimes these incidents may occur in abandoned places, it is difficult for the patient to explain their location or inability to read. On the other hand, these regions may suffer from weakness in social networking

Sudden fire of cars at times may be exposed to fire for a variety of reasons such as fuel-related fires including gasoline leakage or problems with gas pipes, and also fires connected to an electrical fault in the car through the wires connected to the battery, these problems may cause a fire, it is necessary for the competent authorities to know about these fires in a timely manner and not to delay in order not to cause harm to the public utilities of the state.

\section{Challenges}

Gather the information required to successfully implement all project requirements.

To implement this type of project, it needs a lot of learning and knowledge about the devices used in the project and how to effectively connect to the network.

Measuring the level of the type of accident whether it is simple, medium, strong, which sends alerts to the competent authorities.

The sensors are placed in safe and efficient places in the cars so that they cannot be damaged by the impact of the accident and are effective, also it can send alerts

SWOT analysis is a technical term used in project analysis in order to implement successful strategic objectives, as well as knowledge of environmental factors including Internal (strengths and weaknesses) and external (opportunities and threats). These aspects may affect the feasibility of a project. Based on that, in this project, we will use SWOT analysis because it is an important tool in the project in order to reduce risks and failure in the project. (Arabzad, 2014) Fugur1 


\section{Journal of Student Research}

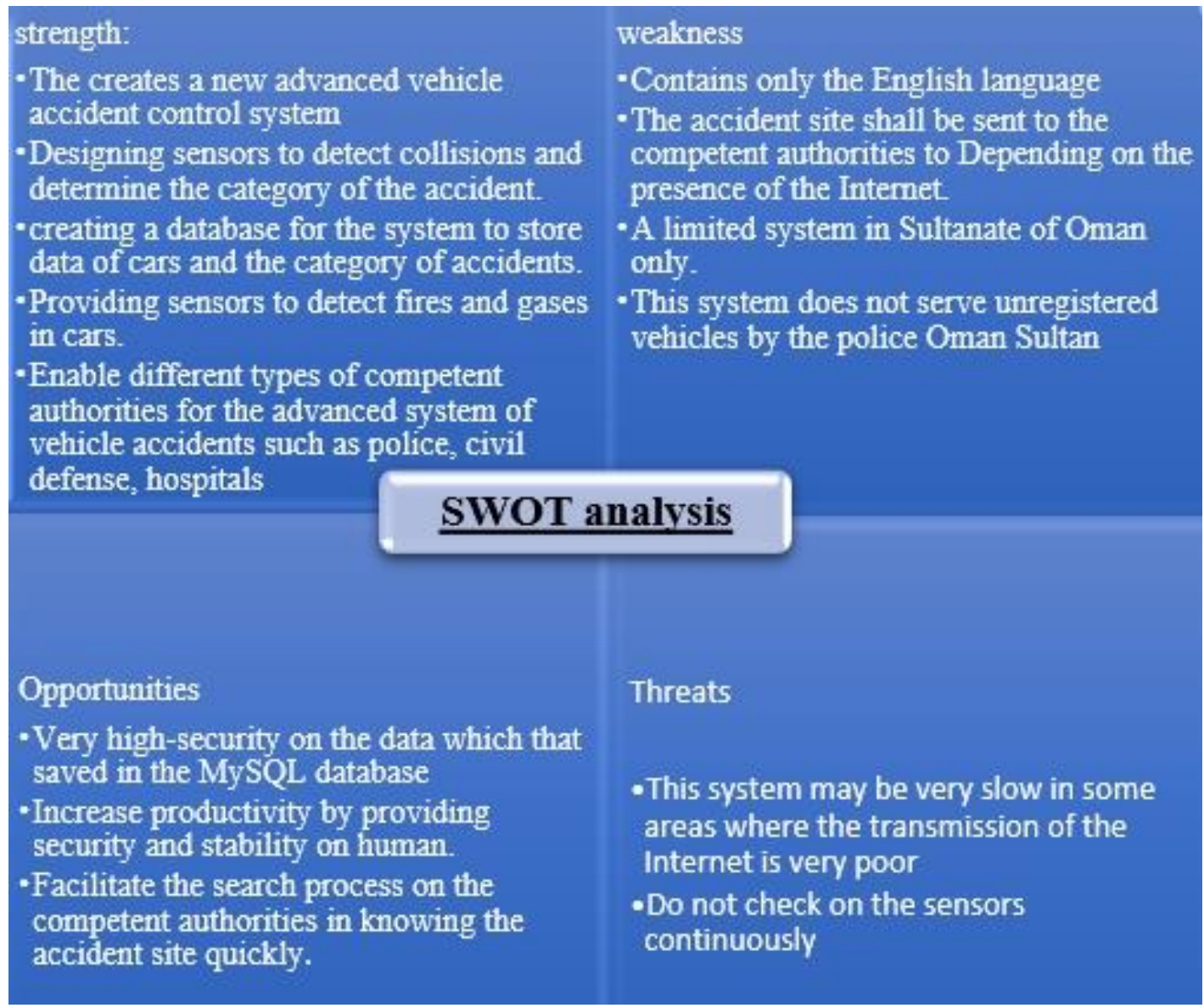

Figure 1. SWOT analysis

\section{Section 2}

Several ways can be followed to get data, collecting the information, analysis, and organization. Study methodology refers to research theory and how to make decisions and its logical sequence. In addition, methodology contains methods to set up, design, constraints, and sample which complement each other, soit can deliver results and data. (Igwenagu, 2016)

Modified Waterfall Model: it is like the waterfall model, where it is used in the same stages the waterfall model. In addition, the modified waterfall is used in providing nutrition and overlap between phases, where it is a repetitive model, So the development steps available via a regular group in order to facilitate flexibility and achievement of features, objectives, and tasks efficiency and quality assurance of documents through the maintenance and implementation of programs at any time and at any stage. Furthermore, the modification waterfall model has different stages in the development of the system, including analysis of requirements, design phase, implementation phase, testing phase, and maintenance phase. Which means when finished from the previous stage development moves to the next stage, also the program can return to the previous phase, unlike the waterfall model cannot go back to the previous stage. 


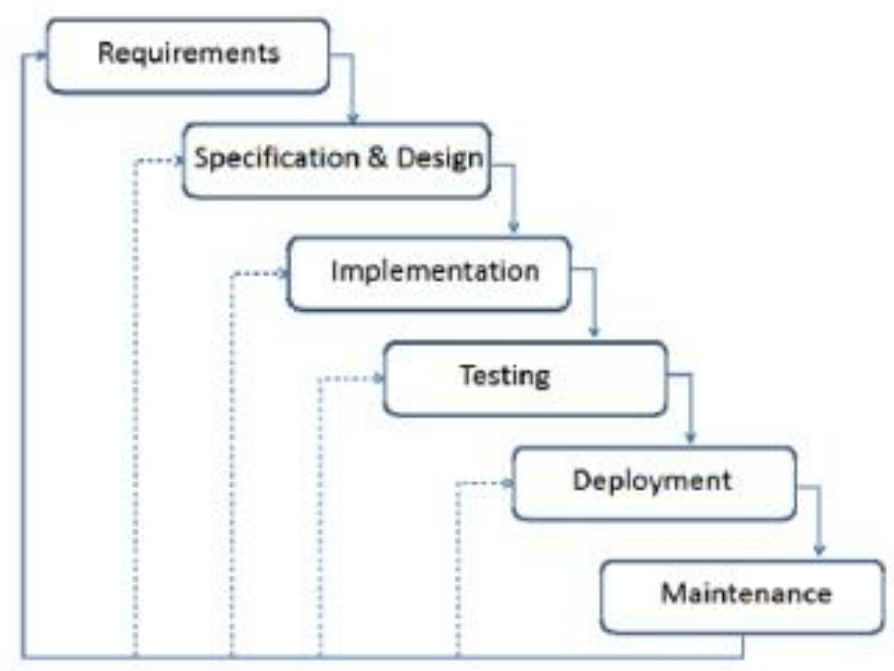

Figure 2. The modified waterfall methodology

This section is about data collection method which is considered as one of the project objectives. Furthermore, data collection process is about conducting a search and collecting information from different and specific variables of the system. Hence, the aim is to gather facts from reliable sources and aspects, so that the individual through which to answer questions access to evidence supporting the project, the data will then be analyzed for correct and convincing answers and credible on the questions that were posted, this is necessary which leads to preservation the safety of completing the search and no errors occur. (Kabir, 2018)

Accordingly, data collection methods have four different types (observation, questionnaires, interviews, and focus group discussions). Thus, through this project, I used the interview method because it is the best for my project, as it is the fastest way to collect information accurately.

is a dialogue between two people (axes? and guests) where questions are asked. The aim is to obtain all the information which is needed for the project. Based on that, I had interviews with stakeholders in this project:

First, an interview with Omani policeman officer in the accidents section in order to know the required procedures and laws when the accident occurred and also find out about the most places where the collision occurs in the vehicle and locate it, also testing the appropriate location for the sensors in the car so that they are effective no matter what the level of the accident.

Second, an interview was conducted with an engineer specializing in networks coverage, in order to know the network coverage in the Sultanate of Oman, so that when the accident occurs the system is effective even in rugged and mountainous places.

Third, we met with a wireless network engineer and discussed to know how to configure the network system for this project for both cases of SIM card and Wi-Fi.

Fourth, we interviewed a Network Hardware Expert for (Arduino, Sensors, GPS Modem, and GSM Modem) and discussed the hardware that we will need to implement the system with the knowledge of the programs required to program these devices which the project will be applied.

Fifth, we visited the Engineering Village and met with someone who specializes in system hardware sales, to know the prices of the devices that the system needs to implement in the project. Figure 3 illustrates Data Analysis 

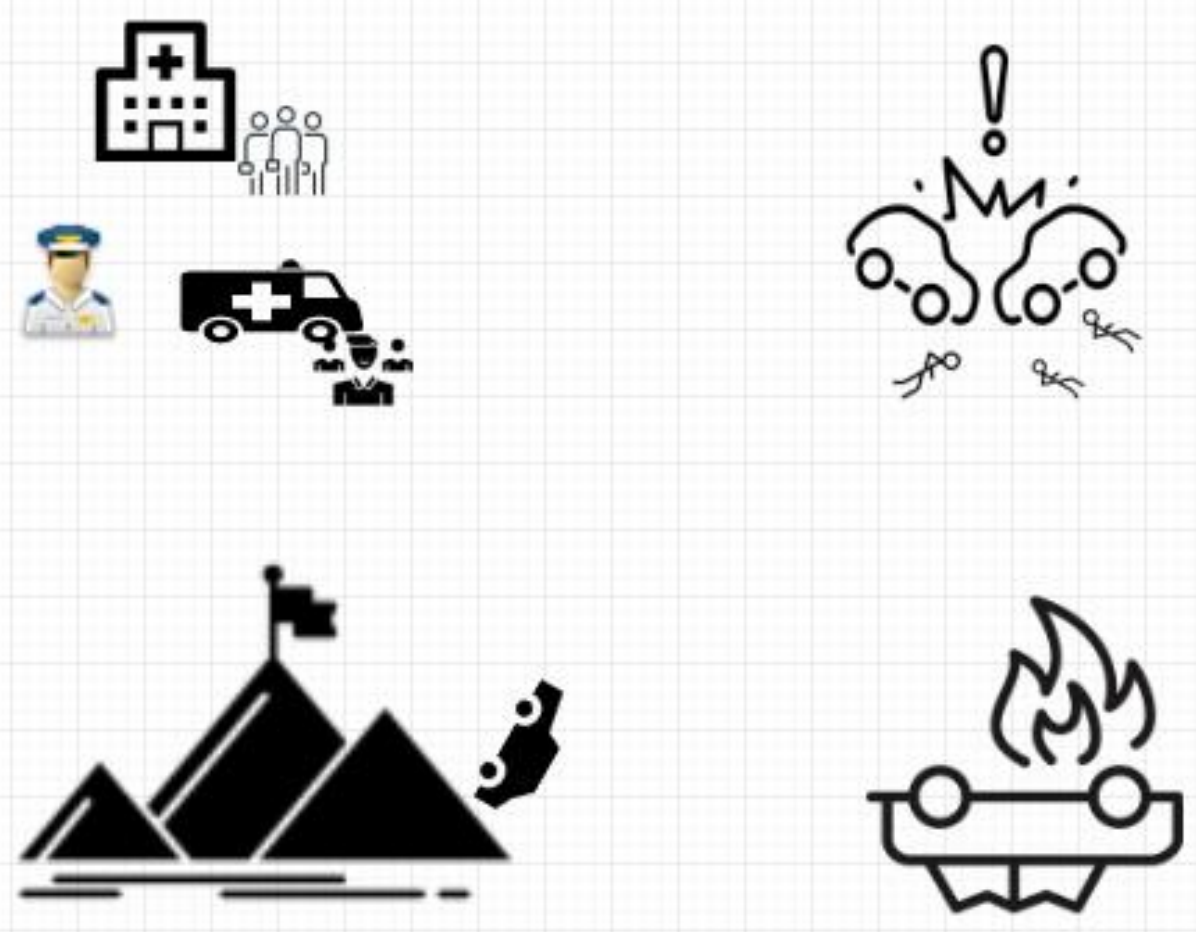

Figure 3. Data analysis

\section{Section 4 Initial design}

Figure 4. The Initial design

"The Advanced System of Vehicle Accidents" this advanced system is characterized by sending an alert to the competent authorities in the event of an accident, so the operation of this system is as follows: is consists of 4 layers:

The first layer is detection and sensors: Which contains several sensors that are associated with the device Arduino mega, including:

GPS modem: The main function of the system is to detect accident locations and accurately transmit location data to Arduino mega.

GSM modem sends all details related to the accidents to the mobile phone number registered in the system

Flame sensor: It is used to send an alarm when a fire occurs to vehicles to facilitate the rescue on time.

Current sensor: It is used to detect the electrical current passing from the battery to the controller 


\section{Journal of Student Research}

Fourth Middle East College Student Research Conference, Muscat, Sultanate of Oman

(Arduino Mega), whereas if the amount of current is decreased to a minimum, it sends an alert to the GSM modem to send a notification to the owner of the vehicle to check the battery current.

Voltage sensor: It measures the AC voltage level of the battery, where the voltage in the battery is 5 volts and therefore if the voltage is decreased to a minimum, it sends an alert to the GSM modem to send a notification to the owner of the car to check of voltage in the car battery.

The second layer edge IOT: After connecting all the sensors in the Arduino Mega, it reads all the data and information associated with the accident and sends it from XBEE Wi-Fi(transmitter) to NODEMCU Wi-Fi then receive the data from via XBEE Wi-Fi(receiver). When NODEMCU connects to modem or router, it sends the data that received over WIFI.

The third layer Core: The modem or router sends the all details to the Internet to connect the idea with users and the competent authorities to know all the accident data in terms of the level and location of the accidents by the cloud database server.

The fourth layer user interface: The cloud database server (webserver) delivers information to the relevant authorities and users to know all details about the accident through (accident level, vehicle details, and location) and they can access the accident location in time without delay.

In addition, "PHP" is a programming language that is used to design web pages on a cloud database server such as social networking sites, also they can connect to a database and how information sites are stored in the database (MySQL). Moreover, MySQL is used in creating the tables which I need from the cloud database server like the level of accident, details of the vehicle and it's the owner and location of the accidents.

\section{Conclusion}

The accident detection system is nowadays one of the most important systems in our daily lives and irreplaceable, which helpes solve a lot of problems in communication between the competent authorities and accident sites. In this research, we developed an accident detection system to prevent a lot of car accidents that cause negative effects on the economic and social levels. it also reduces the loss of human life the main reason for this to delay the competent authorities in the timely delivery of emergency services.

Authorities including details of the vehicle and its owner and the level of the accident (weak, moderate, strong), it also sends a short message bearing the coordinates of the accident site from a trusted source.

For when tracking accident locations for both the effector and the victims in real-time, which contributes in saving a lot of time and effort on them, it also leads an increase in the rate of the rescue of the injured and their survival them so by submitting helping them on time, thus reducing the number of deaths. In addition, this system delivers another medical assistance, which is during a fire in the car sends a letter to the competent authorities.

\section{Acknowledgements}

I would like to express my sincere appreciation and thanks to all those who helped me to encourage and advise me during this study and to help me prepare and write this report. Thank you to the faculty members of the computer department and to the president of the faculty of computers for providing the source of information for this work. I also thank Supervisor Khoula AL-Harthy for guiding me successfully in planning and clearly establishing the project. 


\section{References}

Bhattacharjee, M. (2018). 33.3\% decline in road accidents till March: NCSI - Oman. [online] Muscat Daily News. Available at: https://muscatdaily.com/Archive/Oman/33.3-decline-in-road-accidents-tillMarch-NCSI-58ks [Accessed 6 Jun. 2019].

Butt, S. (2016). [online] Available at: https://www.researchgate.net/publication/317426980_A_Revie w_Paper_on_Accident_Detection_System_Using_Intelligent_Algorithm_for_VANET [Accessed 6 Jun. 2019]

Arabzad, S. (2014). [online] Available at: https://www.researchgate.net/publication/267026741_Ado pting_SWOT_Analysis_to_Strategic_Project_Management_in_Municipality [Accessed 25 Apr. 2019].

Priyanga, R., Rajesh Kumar, D. and J.Yamini, E. (2014). [online] Ijates.com. Available at:

http://www.ijates.com/images/short_pdf/1416059529_P156-161.pdf [Accessed 16 Apr. 2019].

Igwenagu, C. (2016). [online] Available at:

https://www.researchgate.net/publication/303381524_Fundamentals_of_[Accessed 24 May 2019].

Satalkar, B. (2019). Modified Waterfall Model. [online] Techspirited. Available at:

https://techspirited.com/modified-waterfall-model [Accessed 28 May 2019].

rayo, l. (2015). Modified Waterfall Model. [online] prezi.com. Available at:

https://prezi.com/ne8i4-bsjeyf/modified-waterfall-model/ [Accessed 29 May 2019].

Ahmed, S., Ullah, Z. and Ali, H. (2018). [online] Available at: https://www.researchgate.net/publicati on/326092338_Accident_Detection_and_Smart_Rescue_System_using_Android_Smartphone_with_R eal-Time_Location_Tracking [Accessed 16 Apr. 2019].

Asante, B., Ofori Twum, B. and Osei3, P. (2017). [online] Iosrjournals.org. Available at: http://www.iosrjournals.org/iosr-jece/papers/Vol.\%2012\%20Issue\%204/Version-4/B1204041028.pdf [Accessed 16 Apr. 2019].

BRODSKY, H. (2019). [online] Onlinepubs.trb.org. Available at:

http://onlinepubs.trb.org/Onlinepubs/trr/1990/1270/1270- 011.pdf [Accessed 16 Apr. 2019].

Priyanga, R., Rajesh Kumar, D. and J.Yamini, E. (2014). [online] Ijates.com. Available at:

http://www.ijates.com/images/short_pdf/1416059529_P156-161.pdf [Accessed 16 Apr. 2019]. 